\title{
On the spherical nanoindentation creep of metallic glassy thin films at room temperature
}

\author{
T.H. Zhang ${ }^{\mathrm{a}}$, J.H. Ye ${ }^{\mathrm{a}}$, Y.H. Feng ${ }^{\mathrm{b}}$, Y. Ma ${ }^{\mathrm{a}, *}$ \\ a Institution of Micro/Nano-Mechanical Testing Technology \& Application, College of Mechanical Engineering, Zhejiang University of Technology, \\ Hangzhou 310014, PR China \\ b State Key Laboratory of Nonlinear Mechanics (LNM), Institute of Mechanics, Chinese Academy of Sciences, Beijing 100190, PR China
}

\section{A R T I C L E I N F O}

\section{Keywords:}

Nanoindentation

Creep

Metallic glassy film

Strain rate sensitivity

Shear transformation zone

\begin{abstract}
A B S T R A C T
Metallic glassy thin films with eight kind of compositions were successfully prepared on Si substrate by magnetron sputtering. The room-temperature creep tests were performed at plastic regions for each sample relying on spherical nanoindetation. The creep deformations were studied by recording the total creep displacement and strain after $2000 \mathrm{~s}$ holding. More pronounced creep deformation was observed in the sample with lower glass transition temperature $\left(T_{g}\right)$. Strain rate sensitivity (SRS) was then calculated from the steadystate creep and exhibited a negative correlation with increasing $T_{\boldsymbol{g}}$. It is suggested that creep mechanism of the nano-sized metallic glass was $T_{\boldsymbol{g}}$-dependent, according to the demarcation of SRS values. Based on the obtained SRS, shear transformation zone (STZ) size in each sample could be estimated. The results indicated that an STZ involves about 25-60 atoms for the employed eight samples and is strongly tied to $T_{\boldsymbol{g}}$. The characteristic of STZ size in metallic glassy thin films was discussed in terms of applied method and deformation modes.
\end{abstract}

\section{Introduction}

Metallic glass is scientifically defined as amorphous alloy which has a non-crystalline but short-range order structure [1]. Due to its unique atomic configuration, metallic glass is an important part of condensed matter physics. This new-structure material is also promising to be widely utilized in engineering field for excellent mechanical properties such as high strength, large elastic limit and good wear resistance [24]. However the localized shear banding is dominating in plastic deformation of bulk metallic glass, causing limited ductility (even none under tension) that hinders its practical development [5,6]. In the last decade, a strong size effect on deformation behavior was validated in metallic glasses [7-9]. The plasticity could be improved remarkably without sacrificing high strength at micro/nano scale, even combined with the transition of deformation modes (localized to homogeneous) in some compositions. As a consequence, it attracts numerous attentions on nanopillars and thin films, in order to reveal the underlying mechanism of plastic deformation in metallic glass. Nevertheless, the investigations on time-dependent plastic deformation also referred to creep in the micro/nano-sized samples are quite limited [10]. From the viewpoint of engineering, it is essential to evaluate the creep resistance in structure materials especially in the high-temperature applications. Nowadays metallic glasses are more and more adopted in nano-device including micro-electro-mechanical system (MEMS) [11-13], knowing the creep laws of nano-sized metallic glasses in more detail becomes urgent. Based on the scientific interest, creep flow occurs in a homogeneous plastic way with extremely low strain rates, which provides a new insight into the study on the deformation mode transition in metallic glasses.

Relying on nanoindentation, creep behaviors of metallic glasses can be studied at small region, ignoring the restriction of required standard size in traditional creep testing. In addition, the holding stage could be time-saving due to high accuracy for obtaining creep displacement. The stress distribution beneath the indenter is much more complicated than that in uniaxial testing and plastic deformation always occurs before holding stage. Therefore metallic glasses with high glass transition temperature $\left(T_{g}\right)$ can even creep at room temperature by nanoindentation $[14,15]$. The nanoindentation induced creep behaviors of metallic glasses have been qualitatively studied, concerned with the effects of loading rate and imposed initial displacement and/or strain $[16,17]$. In author's previous work, the correlation between creep deformation and loading rate was found to be composition-dependent in metallic glassy thin films [16]. Moreover, creep flow was more pronounced with decreasing thickness in a $\mathrm{Cu}-\mathrm{Zr}-\mathrm{Al}$ thin film [18]. However, it is unable to reach a conclusion on creep characteristic of metallic glasses from the reported results due to different imposed

\footnotetext{
* Corresponding author

E-mail address: may@zjut.edu.cn (Y. Ma).
} 
testing conditions and sample status [14-18]. With this in mind, metallic glassy thin films with eight compositions were carefully prepared by PVD method, ensuring film thickness, surface roughness and structure state are almost equal in different samples. In the present work, we aim to study the creep rule of metallic glasses at microscale and reveal the key factor determining creep flow.

\section{Experimental procedures}

The eight kinds of metallic glassy thin films were deposited on clean silicon wafer in a DC magnetron sputtering system at room temperature in pure argon gas. The power on the target was fixed at $200 \mathrm{~W}$ and working argon pressure was set about 1 mTorr. To ensure the same film thickness, sputtering time for each composition was different that longer duration was required for the sample owns higher melting point. The film thickness was measured by a surface profilometer (Dektak 150), which was around $2 \mu \mathrm{m}$. By means of X-ray energy dispersive spectrometer (EDS) and X-ray Photoelectron Spectroscopy (XPS), the chemical compositions were accurately detected, respectively were $\mathrm{La}_{57} \mathrm{Co}_{18} \mathrm{Al}_{25}, \quad \mathrm{Cu}_{52} \mathrm{Zr}_{48}, \mathrm{Cu}_{44} \mathrm{Zr}_{44} \mathrm{Al}_{12}, \mathrm{Zr}_{55} \mathrm{Cu}_{15} \mathrm{Ni}_{13} \mathrm{Al}_{17}, \quad \mathrm{Ni}_{60} \mathrm{Nb}_{40}$, $\mathrm{Fe}_{70} \mathrm{Y}_{8} \mathrm{~B}_{22}, \mathrm{Co}_{51} \mathrm{Ta}_{9} \mathrm{~B}_{40}$ and $\mathrm{W}_{40} \mathrm{Ru}_{29} \mathrm{~B}_{31}$. The amorphous structures of all the films were confirmed by X-ray diffraction with $\mathrm{Cu} \mathrm{K}$ radiation.

Nanoindentation tests were conducted at constant temperature of $20{ }^{\circ} \mathrm{C}$ on Agilent Nano Indenter G200 with a spherical indenter, whose effective radius is $3.15 \mu \mathrm{m}$ upon calibration on standard fused silica. Constant-load holding method was adopted for the creep experiment. The indenter was held for $2000 \mathrm{~s}$ with a constant loading rate $0.5 \mathrm{mN} / \mathrm{s}$. The applied maximum load was composition-dependent, i.e., $5 \mathrm{mN}$ for $\mathrm{La}-\mathrm{Co}-\mathrm{Al}, 20 \mathrm{mN}$ for $\mathrm{Cu}-\mathrm{Zr}, \mathrm{Cu}-\mathrm{Zr}-\mathrm{Al}, \mathrm{Cu}-\mathrm{Zr}-\mathrm{Ni}-\mathrm{Al}$ and $\mathrm{Ni}-\mathrm{Nb}, 30 \mathrm{mN}$ for $\mathrm{Fe}-\mathrm{Y}-\mathrm{B}, \mathrm{Co}-\mathrm{Ta}-\mathrm{B}$ and $\mathrm{W}-\mathrm{Ru}-\mathrm{B}$, thus the initial indentation displacements before holding stage were roughly the equal. At least 12 independent measurements were performed on each sample. The nanoindentation tests were carried out until thermal drift reduced to below $0.03 \mathrm{~nm} / \mathrm{s}$. Furthermore, drift correction which was calibrated at $10 \%$ of the maximum load during the unloading process would be strictly performed.

\section{Results and discussion}

Fig. 1 shows the typical X-ray diffraction patterns of the asprepared eight films. It is clear that only a broad diffraction peak can be detected in each sample, which represents a crystal-free structure. Fig. 2(a) exhibits the typical creep $P$ - $h$ curve of $20 \mathrm{mN}$-holding test for $\mathrm{Cu}-\mathrm{Zr}-\mathrm{Al}$ film as an illustration. By applying $20 \mathrm{mN}$, the spherical indenter pressed into plastic region that pop-ins can be clearly

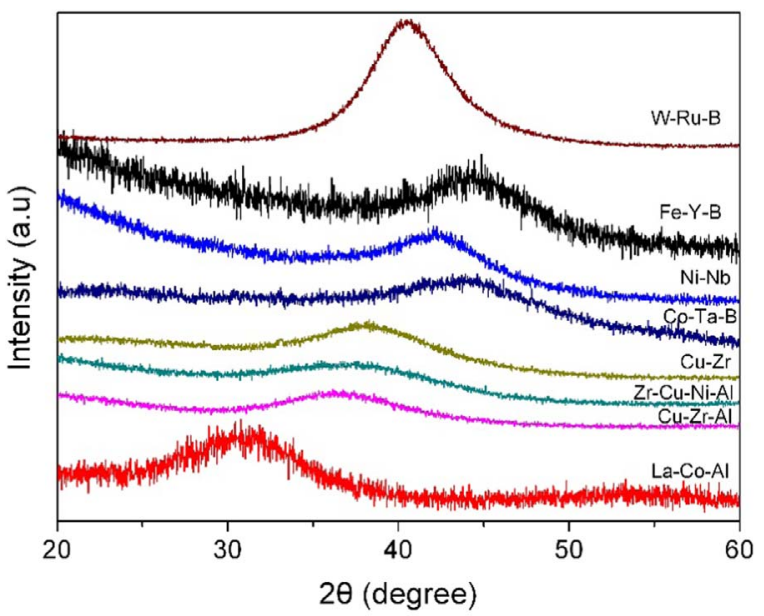

Fig. 1. Typical XRD patterns of all the films.
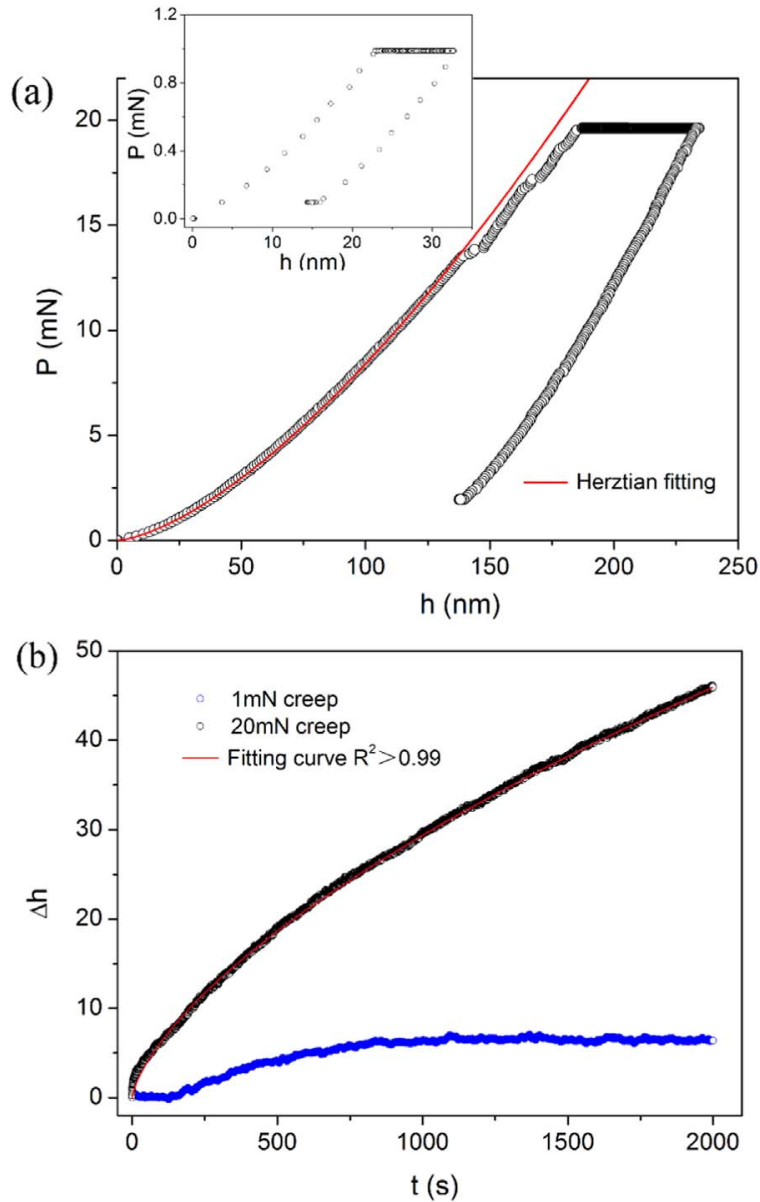

Fig. 2. (a) Representative load-displacement $(P-h)$ curves of the 2000 s-holding creep tests with maximum loads of $20 \mathrm{mN}$ and $1 \mathrm{mN}$ in $\mathrm{Cu}-\mathrm{Zr}-\mathrm{Al}$ film. (b) The corresponding creep displacements versus holding time for $20 \mathrm{mN}$ and $1 \mathrm{mN}$.

observed at the loading sequence. The initial loading curve could be perfectly fitted by the Hertzian elastic contact theory [19], given by:

$P=\frac{4}{3} E_{\mathrm{r}} \sqrt{R} h^{1.5}$

where $E_{r}$ is the reduced elastic modulus which accounts for that the elastic displacement occur in both the tip and sample, $R$ is the tip radius. Thus the elastic modulus $E$ of the sample can be deduced by:

$\frac{E_{\mathrm{s}}}{1-\nu_{s}^{2}}=\left(\frac{1}{E_{r}}-\frac{1-\nu_{i}^{2}}{E_{i}}\right)^{-1}$

In which $v$ is the Poisson's ratio with the subscripts $s$ and $i$ represent the sample and the indenter, respectively. For commonly used diamond tip, $E_{i}=1141 \mathrm{GPa}$ and $v_{\mathrm{i}}=0.07$. In addition, hardness was also calculated from $P-h$ curves with $1 \mathrm{~s}$ holding by the same indenter in Fig. S1. The calculated elastic modulus and hardness were listed in Table 1. The Hertzian fitting line exactly deviated from the $P-h$ curve at the position of first pop-in, further indicating the transition from pure elastic to elastoplastic deformation. The initial indentation strain $\varepsilon_{i}$ before holding stage could be estimated as about $5.5 \%\left(\varepsilon_{i}=0.2(\alpha / R), \alpha\right.$ is the contact radius). It should be noted that the maximum indentation depth was less than $10 \%$ of the film thickness. Hence the substrate influence could be negligible. We also adopted $1 \mathrm{mN}$-holding test (elastic holding) to examine the machine stability and the influence of thermal drift on the experimental result, as shown in the inset of Fig. 2(a). Obviously, creep occurred on the holding stages for both applied loads.

Fig. 2(b) shows the corresponding creep curves during the holding stages, in which creep displacements were plotted with the holding 
Table 1

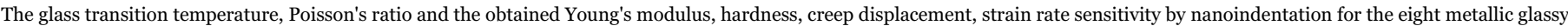
films.

\begin{tabular}{|c|c|c|c|c|c|c|c|c|}
\hline Composition & La-Co-Al & $\mathrm{Cu}-\mathrm{Zr}$ & $\mathrm{Cu}-\mathrm{Zr}-\mathrm{Al}$ & $\mathrm{Cu}-\mathrm{Zr}-\mathrm{Ni}-\mathrm{Al}$ & $\mathrm{Ni}-\mathrm{Nb}$ & Fe-Y-B & Co-Ta-B & $\mathrm{W}-\mathrm{Ru}-\mathrm{B}$ \\
\hline $\mathrm{T}_{\mathrm{g}}(\mathrm{K})$ & 510 & 710 & 730 & 750 & 853 & 850 & 975 & 1020 \\
\hline v & 0.33 & 0.36 & 0.36 & 0.365 & 0.37 & 0.3 & 0.315 & 0.3 \\
\hline $\mathrm{E}(\mathrm{GPa})$ & 58 & 105 & 115 & 110 & 150 & 184 & 200 & 205 \\
\hline $\mathrm{H}(\mathrm{GPa})$ & 3.1 & 7.5 & 8.1 & 7.9 & 9.9 & 11.1 & 14 & 14.5 \\
\hline$\Delta \mathrm{h}(\mathrm{nm})$ & 177 & 67 & 46 & 46.5 & 41.7 & 40.5 & 36 & 25.5 \\
\hline Initial $\varepsilon_{0}$ & $4.8 \%$ & $5.7 \%$ & $5.5 \%$ & $5.5 \%$ & $4.9 \%$ & $5.5 \%$ & $5.2 \%$ & $5.1 \%$ \\
\hline Creep $\Delta \varepsilon$ & $3.8 \%$ & $1.3 \%$ & $1.0 \%$ & $1.1 \%$ & $0.96 \%$ & $0.88 \%$ & $0.83 \%$ & $0.63 \%$ \\
\hline $\mathrm{m}$ & 0.83 & 0.3 & 0.215 & 0.21 & 0.25 & 0.193 & 0.134 & 0.097 \\
\hline
\end{tabular}

time. Two distinct stages can be divided for the creep curves as transient creep and steady-state creep. At the transient stage, the displacement increases relatively fast but the creep rate drops rapidly. Then the creep displacement turns to be slowly and almost linearly increased with time at the steady-state stage. The creep flow of $1 \mathrm{mN}-$ holding test was almost arrested on the steady-state stage. It is reasonable to have minor creep deformation at such small load that the maximum stress beneath the indenter was supposed to be far less than the yield stress of $\mathrm{Cu}-\mathrm{Zr}-\mathrm{Al}$ (namely the stress at first pop-in here). Hence the effect of external disturbance on the time-dependent deformation could be excluded. The displacement on the $20 \mathrm{mN}$ holding stage could be intrinsically due to creep flow of $\mathrm{Cu}-\mathrm{Zr}-\mathrm{Al}$ film. Besides, all the creep measurements showed a good repeatability for each composition, as shown in Fig. S2. The $20 \mathrm{mN}$-creep curve could be perfectly fitted $\left(\mathrm{R}^{2}>0.99\right)$ by an empirical law:

$\mathrm{h}(\mathrm{t})=h_{0}+a\left(t-t_{0}\right)^{\mathrm{b}}+\mathrm{kt}$

Where $h_{O}, t_{O}$ are the displacement and time at the beginning of holding stage (both were zero here), a, b, k are the fitting constants. Fig. S3 shows fitting lines and the parameters for all the films.

The total creep displacements $\Delta h$ of all the films were obtained and their mean values were listed in Table 1 . It is commonly recognized that metals with higher melting point exhibit stronger creep resistance [20]. The experimental results herein followed the same rule that creep was restricted in the sample owns higher $T_{g}$. The correlation between creep displacement and $T_{g}$ could be more intuitively observed in Fig. 3(a). Noticed that creep deformation was much more severe in LaCo-Al than others, which behaves similar to polymers. Creep deformation could be closely related with hardness, which was defined as the ability to resist plastic deformation. Accordingly, it is explainable to have pronounced creep displacement in soft sample. Jang et al. claimed that the initial strain played an important role on spherical nanoindentation creep [17]. Notwithstanding the initial strains here were already in a narrow range of $4.8 \sim 5.7 \%$, it is rational to normalize the creep deformation as $\Delta h / \alpha_{0}\left(\alpha_{0}\right.$ is the contact radius at initial strain) for clearer comparison, as plotted in the inset of Fig. 3(a). The creep strain $\Delta \varepsilon$ for each film was also calculated by $0.2\left(\alpha-\alpha_{o}\right) / R$ [17], as shown in Fig. 3(b). Both the normalized creep deformation and creep strain were in line with the variation trend of creep displacement. The nanoindentation creep strain reached up to $3.8 \%$ for $\mathrm{La}-\mathrm{Co}-\mathrm{Al}$, and still exceeded $0.6 \%$ in Co-Ta-B and W-Ru-B. Such high creep strain is unable to be observed in traditional creep test, in which accelerated stage (the third stage) would appear and induce creep failure.

Indentation creep has been the most extended method to study strain rate sensitivity (SRS) [21]. The value of SRS exponent $m$ can be evaluated via:

$m=\frac{\partial \ln H}{\partial \ln \dot{\varepsilon}}$

In a spherical-tip indentation process, the strain rate during the holding stage can be calculated as $\dot{\varepsilon}=\frac{1}{\sqrt{A}} \frac{d \sqrt{A}}{d t}$ and hardness is defined as $H=P / A$, where $A$ is the contact area equal to $2 \pi R h_{p}$. The plastic
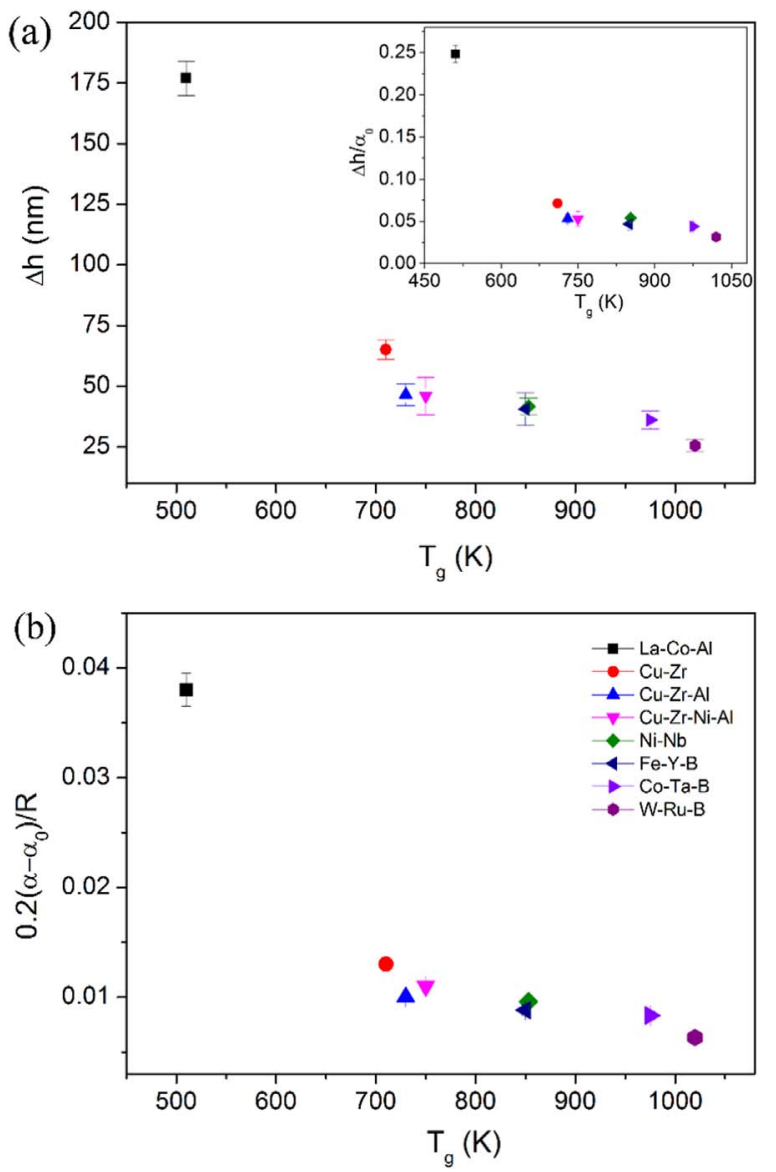

Fig. 3. (a) Total creep displacements and (b) creep strain as a function of glass transition temperature for all the samples.

displacement $h_{p}$ could be deduced as $h_{p}=h_{i}-\varepsilon \times P / S$, in which $h_{i}$ is the total indentation displacement, $\varepsilon=0.75$ for a spherical tip, $S$ is the stiffness deduced from the unloading curve and increased with pressed depth [19]. In the current study, it's unrealistic to detect $S$ at each recorded creep displacement. And the variation of $S$ after $2000 \mathrm{~s}$ holding is no more than $5 \%$ for each sample, by comparing the $S$ obtained from the unloading curves in Fig. S1. For simplicity, the $S$ obtained from the creep unloading curve was adopted to calculate hardness and strain rate (noticed that SRS is obtained from the steadystate creep curve, wherein $S$ is close to the end value of creep). Fig. 4(a) shows the typical fitting line of $\mathrm{Cu}-\mathrm{Zr}-\mathrm{Al}$ creep curve. Fig. 4(b) and (c) show the variation of strain rate and hardness as a function of creep time deduced from the fitted line, respectively. Fig. 4(d) shows the logar-logar correlation between hardness and strain rate. And $m$ can be obtained by linearly fitting the part of steady-state creep. For reliability, 6-9 effective creep curves were employed to reach an average value of SRS for each sample, as listed in Table 1. SRS is extraordinary high in 



Fig. 4. (a) Fitting line for the creep curve; (b) strain rate versus holding time; (c) hardness versus holding time; (d) the log-log correlation between hardness and strain rate.

La-Co-Al approaching 0.9 and then slightly decreases from 0.3 in $\mathrm{Cu}-\mathrm{Zr}$ to 0.097 in W-Ru-B. Fig. 5 clearly depicts the variation trend of the estimated $m$ as a function of $T_{g}$ in metallic glass thin films. Within the large $T_{g}$ range of samples from about $500-1000 \mathrm{~K}$, the SRS generally reduced with increasing $T_{g}$. It has been revealed that SRS of metallic glasses decreased with increasing strain rate and/or pressed depth by nanoindetation creep test $[22,23]$. The glass transition temperature $\left(T_{g}\right)$ is a vital thermodynamic parameter of metallic glass, which could be closely tied to the atomic structure and plastic deformation [24]. To the authors' best knowledge, investigation on the correlation between SRS and intrinsic parameters of metallic glass is rare. In Pan's work, SRS monotonically increased with decreasing Poisson's ratio in bulk metallic glasses by a rate-jump method [25]. However, we are unable to establish such correlation between SRS and Poisson's ratio in the present work. It should be emphasized that the present study do not

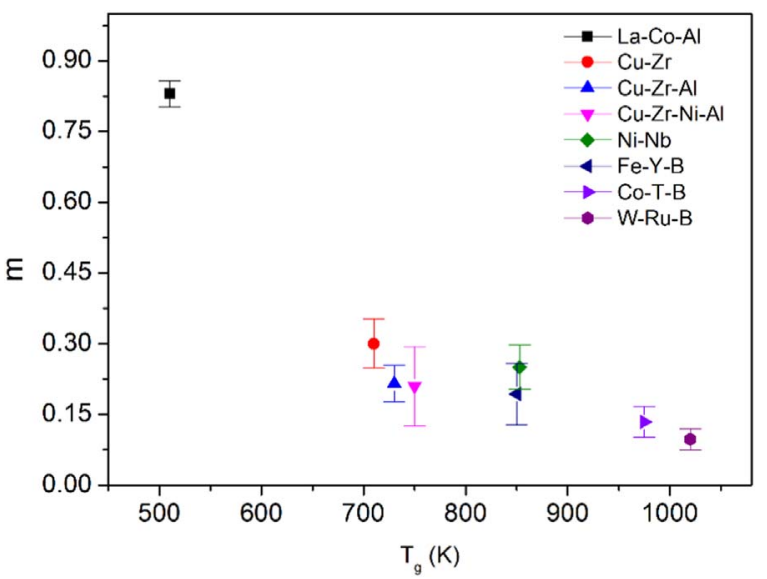

Fig. 5. SRS obtained from steady-state creep as a function of $T_{\boldsymbol{g}}$ for all the sample. conflicted with the previous report, for the experimental results obtained by the two methods (creep \& rate-jump) could not be compared to each other directly. The rate-jump method is conducted under quasi-static loading and suffered instantaneous plastic deformation, whose results are always a magnitude less than those by creep [26].

In crystalline alloys, nanoindentation creep could be due to various possible mechanisms such as plasticity (dislocation glide), power law creep (climb plus glide), power law breakdown (glide plus climb), recovery (dislocation climb) and diffusion (volume, grain boundary or dislocation pipe) [27]. While the creep mechanism of metallic glasses is not well developed, free volume creation and annihilation, interfacial diffusion and shear transformation zone (STZ) evolution were thought to support the creep flow beneath the indenter [10, 23, 28]. From the viewpoint of crystalline alloys, the creep mechanism could be related to the SRS $m$ or stress exponent $n(n=1 / m$ in form). For example, diffusion creep $(n=1)$, grain boundary sliding creep $(n=2)$ and dislocation-dominant creep $(n=3-8)$ could be constructed. It is worth noting that the possible plastic mechanisms of metallic glass are free volume and STZ which could induce localized shear bands. During the steadystate creep flow, the indentation strain rate was calculated about $10^{-5}$ $1 / \mathrm{s}$ and the corresponding effective uniaxial strain rate could be supposed to be $10^{-6} 1 / \mathrm{s}$ according to Oliver's work [29]. Under such low strain rate, the localized shear banding can be restricted in metallic glassy thin films [30]. A "homogeneous" plastic flow could thus be expected during creep. For the pressed depth has already been beyond $150 \mathrm{~nm}$ for each film, the effect of interfacial diffusion could be minor. The evolution of free volume and/or STZs beneath the indenter would induce creep flow. In author's previous work, the localized plastic deformation could be hindered with increasing the value of $\frac{T}{T_{g}}$ in metallic glass thin film, i.e., promoting the "homogeneous" flow [30]. It could be explained that the critical activation energy of the plastic units is decreased at higher $\frac{T}{T_{g}}$ [31], thus the structure mobility is enhanced. 
Table 2

The mean atomic radius, creep hardness, shear modulus and the estimated STZ size, activation energy for the eight metallic glassy films.

\begin{tabular}{|c|c|c|c|c|c|c|c|c|}
\hline Composition & La-Co-Al & $\mathrm{Cu}-\mathrm{Zr}$ & $\mathrm{Cu}-\mathrm{Zr}-\mathrm{Al}$ & $\mathrm{Cu}-\mathrm{Zr}-\mathrm{Ni}-\mathrm{Al}$ & $\mathrm{Ni}-\mathrm{Nb}$ & Fe-Y-B & Co-Ta-B & W-Ru-B \\
\hline $\mathrm{r}(\mathrm{nm})$ & 0.168 & 0.144 & 0.144 & 0.148 & 0.136 & 0.129 & 0.116 & 0.124 \\
\hline $\mathrm{H}_{\mathrm{c}}(\mathrm{GPa})$ & 0.98 & 5.4 & 6.2 & 6.1 & 7.4 & 9 & 11 & 11.4 \\
\hline $\mathrm{G}$ & 22 & 38.6 & 42.5 & 40.6 & 54.9 & 70.8 & 76 & 77.7 \\
\hline$\Omega$ (atom) & 26 & 24 & 29 & 29 & 31 & 37 & 55 & 61 \\
\hline $\mathrm{W}_{\text {stz }}(\mathrm{KJ} / \mathrm{mol})$ & 12 & 12.4 & 16.3 & 16.9 & 19.1 & 25 & 29.2 & 40.1 \\
\hline
\end{tabular}

The STZ volume can be accordingly estimated by the cooperative shear model (CSM) of Johnson and Samwer [32], based on the obtained SRS from creep. In the CSM model, the activation energy of the STZ is defined as:

$W_{S T Z}=4 R_{0} G_{0} \gamma_{C}^{2}\left(1-\tau / \tau_{0}\right)^{3 / 2} \xi \Omega$

Thus the correlation between STZ volume $\Omega$ and activation volume $V^{*}$ can be obtained by directly differentiation of the activation energy, given by:

$\Omega=\frac{\tau_{0}}{6 R_{0} G_{0} \gamma_{C}^{2} \xi\left(1-\tau / \tau_{0}\right)^{1 / 2}} V^{*}$

Where $R_{O} \approx 1 / 4$ and $\xi \approx 3$ are constants, $\tau$ and $\tau_{O}$ are threshold shear resistances at temperature $T$ and $0 \mathrm{~K}, G_{O}$ is the shear modulus at $0 \mathrm{~K}$, the average elastic limit $\gamma_{C} \approx 0.027, \tau_{O} / G=0.036$, the value of $\tau / \tau_{O}$ can be estimated from the constitutive equation

$\tau / G=\gamma_{C 0}-\gamma_{C 1}\left(T / T_{g}\right)^{2 / 3}$,

where $\gamma_{C 0}=0.036 \pm 0.002, \gamma_{C 1}=0.016 \pm 0.002$, shear modulus $G \approx \frac{E}{2(1+\nu)}$ has a weak temperature dependency for a metallic glass and would not affect the calculation according to the dense-packing hard-sphere model of metallic glass [33], wherein the average atomic radius $r \approx\left(\sum_{i}^{n} A_{i} r_{i}^{3}\right)^{1 / 3}, A_{i}$ and $r_{i}$ are atomic fraction and atomic radius of each element, respectively. STZ activation volume $V^{*}$ can be expressed as:

$V^{*}=\frac{k T}{m \tau_{y}}$

Here $\tau_{y}$ is the critical shear stress upon the traditional tensile or compressive tests, has an empirical correlation as $\tau_{y} \approx H / 3 \sqrt{ } 3$. The average hardness $H_{c}$ during the steady-state creep was adopted to estimate the flow stress. Once the STZ activation volume $V^{*}$ is determined, STZ size and activation energy of each film could be calculated from formula (6) and (5).

The computed results of STZ size $\Omega$ and activation energy $\mathrm{W}_{\text {stz }}$ were summarized in Table 2, as well as the estimated shear modulus, atomic radius and creep hardness for all the films. The obtained STZ sizes are in the range of 25-60 atoms and in a good agreement with the previous experiment and simulation reports [34-36]. Overall the STZ size and activation energy are increased with increasing $T_{g}$ as shown in Fig. 6. Perriere et al. studied the chemical effects on the STZ volumes of $\mathrm{Cu}-\mathrm{Zr}$ based metallic glasses by nanoindentation creep and found a negative correlation with elastic modulus [37]. It could be reasonable that a metallic glass with a high $T_{\boldsymbol{g}}$ has a strong atomic bonding, i.e., $E$ is generally proportional with $T_{g}$. However, the present result is currently contrary to Perriere's. In Perriere's work, the decline of STZ volume was relatively weak $\left(0.205 \mathrm{~nm}^{3}\right.$ to $\left.0.167 \mathrm{~nm}^{3}\right)$ and the range of elastic modulus was too narrow $(80.7-99.4 \mathrm{GPa})$ to reach a universal law. While the STZ size is roughly reduce from 60 atom to 25 atom with the decrease of Young's modulus from $205 \mathrm{GPa}$ to $58 \mathrm{GPa}$ in the present study. Furthermore, Pan et al. claimed that STZ size was increased with Poisson's ratio by a rate-jump method and large STZs are facilitated to the plasticity of bulk metallic glasses [25]. However, STZ size was found to decrease with increasing Poisson's ratio in author's previous study by a statistic method, which relies on the distribution of yield stress [38]. As it was aforementioned that distinct results would be
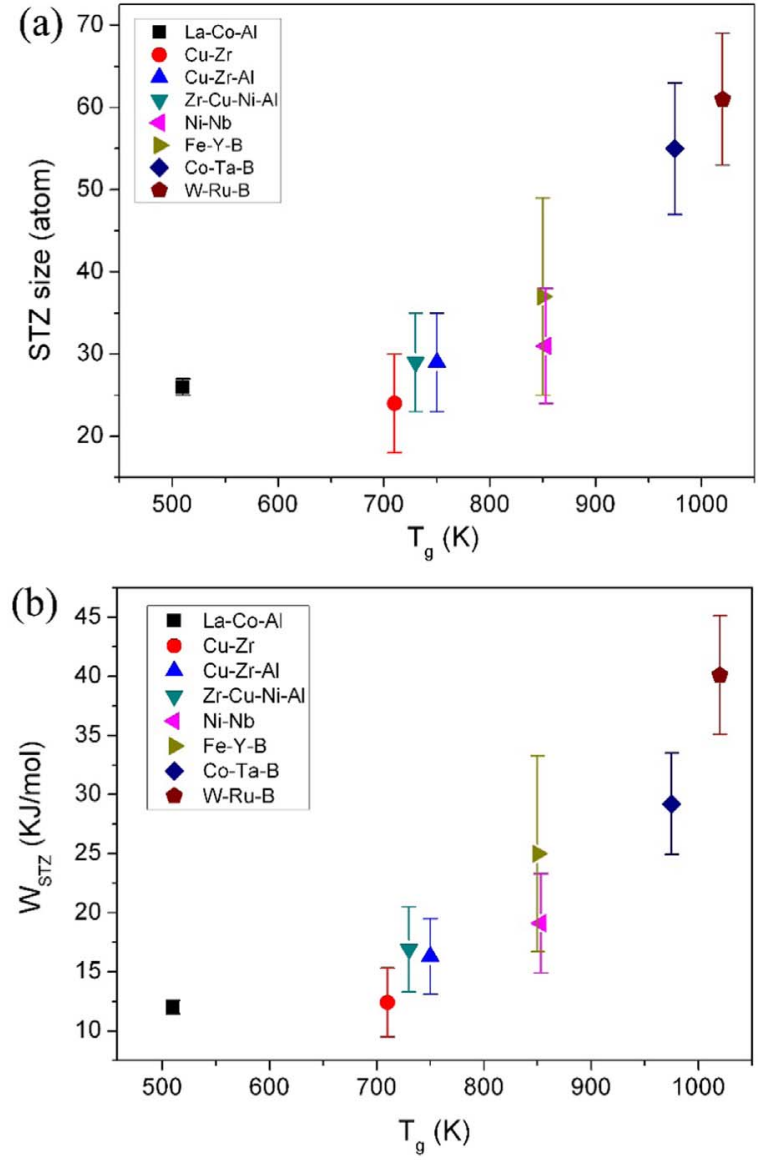

Fig. 6. STZ size $\Omega$ and activation energy $\mathrm{W}_{\text {stz }}$ of the eight metallic glassy thin films as a function of $T_{g}$

generated by different methods on calculating strain rate sensitivity, the experimental conclusion on the characteristic of STZ size would also be method-dependent. In addition, STZ size was revealed to be correlated with strain rate [39] and temperature [31], as well as the structure state $[40,41]$. Be distinct from the previous reports [25, 31, $38-41]$, the strain rate herein was extremely low and the film deformed in a non-localized manner. It suggests that the estimated STZ size is $T_{\boldsymbol{g}}$ or $E$-dependent in homogeneous flow while Poisson's ratio-dependent in localized deformation. It's worth noting that the STZ size and activation energy in La-Co-Al film are very close to those in $\mathrm{Cu}-\mathrm{Zr}$ film, though the $T_{g}$ of La-Co-Al film is far less than $\mathrm{Cu}-\mathrm{Zr}$ film. It implies a possibility that at least $\sim 25$ atoms are required to construct an STZ in a metallic glass [40], though it needs more evidences on both experiment and simulation.

\section{Conclusion}

Creep behavior of metallic glassy films was studied at about $5 \%$ plastic strain by nanoindentation with a spherical tip. All the creep 
curves could be perfectly fitted by an empirical law. The total creep displacements and strains after $2000 \mathrm{~s}$ holding were recorded for all the films. The sample with higher $T_{\boldsymbol{g}}$ exhibited stronger creep resistance. Through the fitting line, strain rate sensitivity was estimated from the steady-state part that 0.83 for La-Co-Al film and $0.1-0.3$ for the others. It's suggested that the creep mechanism of La-Co-Al film might be distinct from the others. Moreover, the STZ size and activation energy of each film were calculated based on the value of SRS. It was revealed that the sample with higher $T_{\boldsymbol{g}}$ owns larger STZ size and higher activation energy by the nanoindentation creep method.

\section{Acknowledgement}

The support from the National Natural Science Foundation of China (Grant Nos. 11502235, 11672356) are gratefully acknowledged.

\section{Appendix A. Supporting information}

Supplementary data associated with this article can be found in the online version at doi:10.1016/j.msea.2017.01.018.

\section{References}

[1] W. Klement, R. Willens, P. Duwez, Nature 187 (1960) 869-870.

[2] J.F. Loffler, Intermetallics 11 (2003) 529-540.

[3] C.A. Schuh, T.C. Hufnagel, U. Ramamurty, Acta Mater. 55 (2007) 4067-4109.

[4] A. Inoue, B. Shen, H. Koshiba, et al., Nat. Mater. 2 (2003) 661-663.

[5] H.J. Leamy, H.S. Chen, T.T. Wang, Metall. Trans. 3 (1972) 699-708.

[6] A. Argon, Acta Metal, Mater 27 (1979) 47-58.
[7] H. Guo, P.F. Yan, Y.B. Wang, et al., Nat. Mater. 10 (2007) 735-739.

[8] D. Jang, J.R. Greer, Nat. Mater. 3 (2010) 215-219.

[9] D. Tönnies, R. Maaß, C.A. Volkert, Adv. Mater. 32 (2014) 5715-5721.

[10] B.G. Yoo, J.H. Oh, Y.J. Kim, et al., Int. J. Plast. 37 (2012) 108-118.

[11] G. Kumar, H.X. Tang, J. Schroers, Nature 457 (2009) 868-872.

[12] Y. Saotome, K. Imai, S. Shioda, et al., Intermetallics 10 (2002) 1241-1247.

[13] J. Schroers, Q. Pham, A. Desai, J. Micro. S 16 (2007) 240-247.

[14] Y. Huang, J. Shen, Y. Chiu, et al., Intermetallics 17 (2009) 190-194.

[15] B.G. Yoo, I.C. Choi, Y.J. Kim, et al., Mat. Sci. Eng. A 577 (2013) 101-104.

[16] Y. Ma, J.H. Ye, G.J. Peng, et al., Mat. Sci. Eng. A 622 (2015) 76-81.

[17] B.G. Yoo, K.S. Kim, J.H. Oh, et al., Scr. Mater. 63 (2010) 1205-1208.

[18] Y. Ma, G.J. Peng, W.F. Jiang, et al., J. Non-Cryst. Solids 442 (2016) 67-72.

[19] K.L. Johnson, Cambridge University Press, UK, 1987.

[20] M.A. Meyers, A. Mishra, D.J. Benson, Prog. Mater. Sci. 51 (2006) 427-556.

[21] I.C. Choi, B.G. Yoo, Y.J. Kim, et al., J. Mater. Res 27 (2012) 3-11.

[22] B.G. Yoo, J.H. Oh, Y.J. Kim, et al., Intermetallics 18 (2010) 1898-1901.

[23] F. Wang, J.M. Li, P. Huang, et al., Intermetallics 38 (2013) 156-160.

[24] J. Lu, G. Ravichandran, W.L. Johnson, Acta Mater. 51 (2003) 3429-3443.

[25] D. Pan, A. Inoue, T. Sakurai, et al., Proc. Natl. Acad. Sci. 105 (2008) 14769-14772.

[26] A. Bhattacharyya, G. Singh, K.E. Prasad, et al., Mat. Sci. Eng. A 625 (2015) 245-251.

[27] W.B. Li, J. Henshall, R. Hooper, Acta Metal. Mater. 39 (1991) 3099-3110.

[28] Y. Ma, G.J. Peng, Y.H. Feng, et al., Mat. Sci. Eng. A 651 (2016) 548-555.

[29] W.H. Poisl, W.C. Oliver, B.D. Fabes, J. Mater. Res 10 (1995) 2024-2032.

[30] Q.P. Cao, Y. Ma, C. Wang, et al., Thin Solid Films 561 (2014) 60-69.

[31] C.A. Schuh, A.C. Lund, J. Mater. Res 19 (2004) 2152-2158.

[32] W. Johnson, K. Samwer, Phys. Rev. Lett. 95 (2005) 195501.

[33] J.D. Bernal, Nature 185 (1960) 68-70.

[34] M. Zink, K. Samwer, W.L. Johnson, et al., Phys. Rev. B 73 (2006) 172203.

[35] M. Heggen, F. Spaepen, M. Feuerbacher, J. Appl. Phys. 97 (2005) 033506.

[36] A.S. Argon, L.T. Shi, Acta Met. 31 (1983) 499-508.

[37] L. Perrière, S. Nowak, S. Brossard, et al., Scr. Mater. 68 (2013) 183-186.

[38] Y. Ma, G.J. Peng, T.T. Debela, et al., Scr. Mater. 108 (2015) 52-55.

[39] I.C. Choi, Y. Zhao, B.G. Yoo, et al., Scr. Mater. 66 (2012) 923-926.

[40] I.C. Choi, Y. Zhao, Y.J. Kim, et al., Acta Mater. 60 (2012) 6862-6868.

[41] D. Pan, Y. Yokoyama, T. Fujita, et al., Appl. Phys. Lett. 95 (2009) 141909. 